\title{
Quantifying Wood Decay in Sydney Bluegum (Eucalyptus saligna) Trees
}

\author{
Denise Johnstone, Michael Tausz, Gregory Moore, and Marc Nicolas
}

\begin{abstract}
The evaluation of decayed wood in a tree is essential for tree risk assessment in arboriculture. It is not feasible in practice to measure the amount of wood decay in all the wood of every tree. Therefore, the capacity of a single measurement taken in cross-section to approximate the volume of decay in the wood of a whole tree is the focus of this study. The volume of wood decay in Eucalyptus saligna trees was estimated post harvest by measuring the whole tree wood density of 36 trees. Linear, logarithmic, and multiple regression statistical models were used to examine whether whole tree wood density data could be correlated with three ways of directly measuring wood decay in a single cross-section, two prior to tree felling and one post felling method. The decay estimation techniques were measured in cross-section—a Picus ${ }^{\circledR}$ Sonic Tomograph system, an IML-Resi system, and a visual method. In this study the Resi System for estimating wood decay showed a correlation with whole tree wood density in the entire tree whereas the Picus system and the visual method did not show any statistical correlation with whole tree wood density.

Key Words. Eucalypts; Hazard Trees; Picus ${ }^{\circledast}$ Sonic Tomograph; Resi; Resistograph; Tree Failure; Tree Risk Analysis; Wood Decay.
\end{abstract}

Evaluating the amount of decayed wood in a tree is essential for tree risk assessment. It is not feasible in practice to measure the amount of wood decay in all the wood of every tree in an urban landscape. The extent of decay in Eucalyptus globulus and Eucalyptus nitens is greater axially than either radially or tangentially (Deflorio et al. 2007), suggesting a stem measurement may detect wood decay, if present, in Eucalyptus saligna. Therefore, the capacity of a single measurement taken in cross-section to approximate the volume of decay in the wood of a whole tree at the time of testing is the focus of this study. This study does not attempt to predict the progression of decay within trees over time.

Field devices for measuring decay in the cross-sections of trees vary greatly in their operating principles and are often similar to the equipment used for measuring wood density, as decay results in a decrease in wood density or mass (Beall and Wilcox 1987). Two of the most common devices for quantifying wood decay in urban trees are the Argus-Picus Sonic Tomograph, which records the time of transmission of multiple acoustic stress waves through the stem of the tree in a cross-section, and the IML-Resi which is a constant feed drill that records "resistance" on a graph trace. The aim of the investigations described in this paper was to examine whether quantifying the area of decay in cross-section could be extrapolated to estimate the volume of wood decay in Eucalyptus saligna. Methods using the Resi and the Picus were used to estimate wood decay in a trunk cross-section of the trees before they were felled, and a visual method was used after felling.

Electrical conductivity meters such as the Shigometer were not used because interpreting data from these instruments has been shown to be difficult in certain genera - particularly Eucalyptus (Wilkes and Heather 1983). The Fractometer was not chosen because the $5 \mathrm{~mm}$ core sample required by the instrument proved too brittle to be assessed successfully in Eucalyptus globulus in a study by Matheny et al. (1999). Currently available devices are similar to the ones used in the experiment, although they may have more sophisticated data recording, software, and data processing.

Field instruments quantify decay in small sections only, so the methods of wood decay estimation were compared to an estimation of the density of the wood in each tree or the "whole tree wood density" to gauge which method best reflected the amount of wood decay in the entire tree. It must be emphasized that in this study, "whole tree wood density" includes trunk or branch wood sections that may be hollow or very decayed, rather like a pipe, and hence have very low density. Thus, whole tree wood density is a measure of wood decay in the entire tree. Whole tree wood density in this study should not be confused with "basic wood density." There are five standard ways of describing wood density in the timber industry: oven-dry density, air-dry density, green density, nominal density, and basic density (Walker et al. 1993). All of these density measurements are taken on wood samples that appear completely sound (nondecayed) as were the basic wood density samples in this study. Thus, the measurement of basic wood density in this study does not relate directly to the decayed wood in the trees, unlike the measure of whole tree wood density, which includes visibly decayed wood.

Wood decay was measured in plantation trees as this enabled a statistically significant number of even aged trees to be measured with relative ease, and to reduce the variation in whole tree wood density data that may be due to the environmental effects on branch growth such as plant-soil-nutrient interactions and climate (Casella and Sinoquet 2003). Open grown or urban trees would not have been suitable to test the effectiveness of single location decay methods for describing the volume of wood decay 
in a tree as the ratio of branch wood to trunk wood would vary considerably due to environmental considerations and tree age. However, the success of the methods in the context of a plantation can be applied to urban trees. The three decay assessment methods were also compared with the percentage wood moisture content and basic wood density to assess whether the decay measurement methods were affected by these two properties.

\section{MATERIALS AND METHODS}

All investigations on the trees in this study were conducted on 36 Eucalyptus saligna Sm (Bateman's Bay) trees growing in a eucalypt plantation at Tostaree in country Victoria, Australia (latitude $37^{\circ} 47^{\prime}$ longitude $\left.148^{\circ} 11^{\prime}\right)$. The trees were 18 -years-old, with heights between 17 and $27 \mathrm{~m}$, and diameters at $1.3 \mathrm{~m}$ in height ranging from 142 to $318 \mathrm{~mm}$. Approximately 100 E. saligna were assessed using the Visual Tree Assessment (VTA) method (Mattheck and Breloer 1994; Mattheck 2007). Features such as bulges in the trunks or poorly occluded branch stubs were taken as indicators of possible wood decay. This method was used to choose 36 trees for the study rather than random sampling in order to provide a range of decayed wood from decayed to very little decay as canvassed by Wang et al. (2009). Break or edge trees were not included in the sample as they would have had a higher ratio of branch to trunk wood, introducing uncontrolled variation into the study.

\section{Whole Tree Wood Density Estimation}

The whole tree wood density data included in the measurement any low density decayed wood, or any absence of wood, due to wood decay in the stem or branches.

The process for calculating whole tree wood density involved four steps:

(1) All trunk wood sections were weighed immediately after cutting (fresh or 'green' weight) and reduced by the percentage of moisture content in the wood. Wood moisture content was estimated as: $\{$ [original (wet) weight - oven dry weight]/original (wet) weight \} x 100 (Walker et al. 1993).

(2) The branches and upper canopy of the trees were weighed (fresh weight) and the leaf fresh weight was subtracted from the branch and upper canopy weight.

(3) The green branch wood weight was then reduced by the percentage of wood moisture content in a small branch sample using the same method as for the trunk sample described earlier.

(4) The resultant dry wood weights for trunk and branches were added and divided by the total (branch and trunk) fresh wood volume (calculated as for a cylinder, but measured at every $1 \mathrm{~m}$ for the trunk).

The resultant parameter was thus defined as whole tree wood density.

\section{Wood Decay Estimation Method \#1: The Picus System}

The first method for measuring decay used the Argus-Picus Sonic Tomograph, which produced a "false color" image from acoustic time of flight raw data gathered in cross-section. Because the instrument software does not allow for any other form of data output and precludes access to raw data, resultant images were analyzed using the image processing and analysis software ImageJ version $1.40 \mathrm{~g}$ (Rasband 2008). The method relies on the experienced use of both the Argus-Picus Sonic Tomograph and image analysis software.

The trees were tested with the Picus Sonic Tomograph at $0.3 \mathrm{~m}$ in height from ground level (Figure 1). This height was chosen as a test height for the cross-sections as the wood volume was greatest at the base of the trees, $11 \%-19 \%$ of the total wood volume of the trees was found to be from ground level to $1 \mathrm{~m}$ in height. Therefore, measuring a cross-section low in the tree would include more wood than testing at higher points on the tree. In trees without cavities or fungal fruit bodies, the sections with the highest percentage of decay were usually found to be at the base in previous studies on Eucalypts (Johnstone 2005; Johnstone et al. 2007). Furthermore more wood decay extends from stem wounds rather than branch wounds in E. globulus and $E$. nitens, similar species to E. saligna (Deflorio, et al. 2007). Estimating the percentage of wood decay from sections at $0.3 \mathrm{~m}$ may therefore slightly overestimate the volume of wood decay in the entire tree, but it does avoid the problem of missing existing decayed wood entirely.

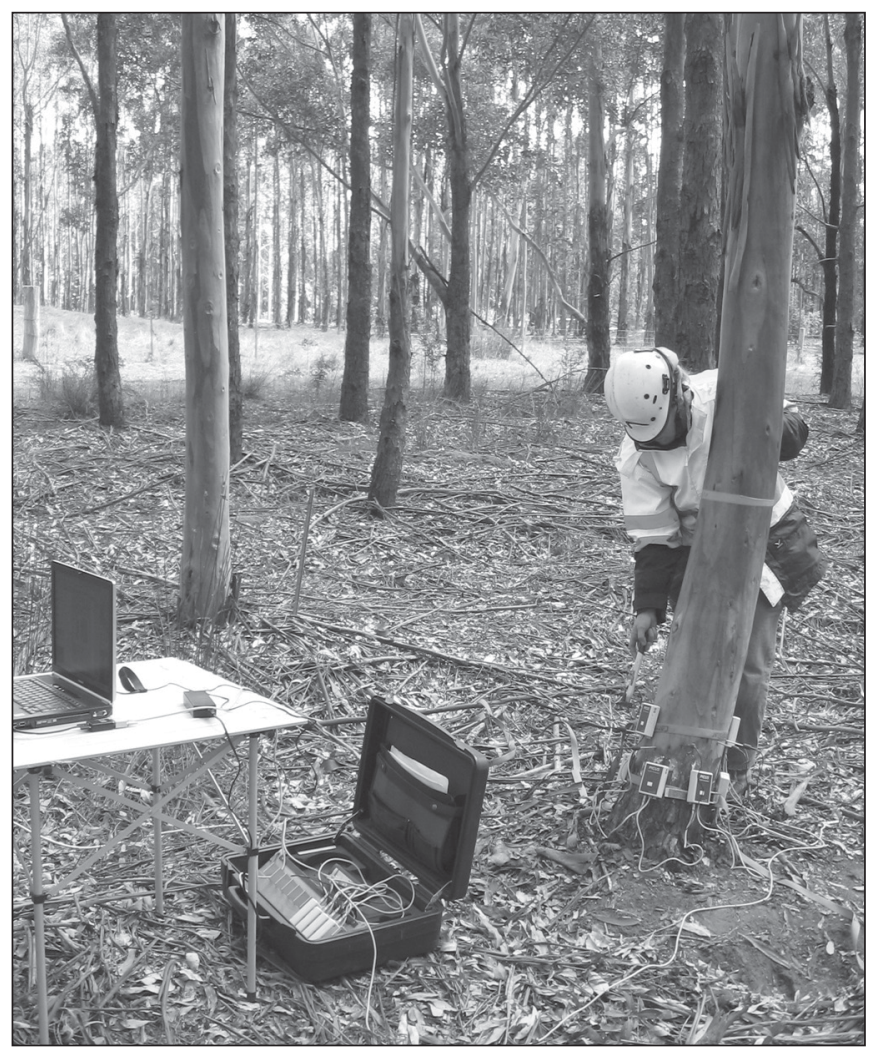

Figure 1. Acoustic stress wave being sent by a hammer tap to the sonic tomograph sensor array, later processed by the interface box and sent to a computer. Photograph courtesy of Matthew Sauvarin.

The trees were tested as described in the Picus manual (Anonymous 2004), except that the sensors where placed closer together than recommended by the manual (Anonymous 2004). Placing the sensors at a minimum distance of 75 $\mathrm{mm}$ rather than $150 \mathrm{~mm}$ improved the accuracy of the Picus image as more sensors could be used; interferences or other problems with the collection of acoustic data were not observed as a result of this method. Placing sensors as close as 
possible also reduces the possibility of incorrect calibration of sound wood by the device, because the sonic signals are more likely to pass through completely sound wood at least once.

The perimeter diagrams generated by the 2004 Picus software program were smoothed by hand and the cross-sectional area of the section was then calculated using the ImageJ image analysis software. Initially, the colors on the Picus images were interpreted with reference to the manufacturers' recommendations - interpreting the image according to the hue of the image, that is, green, violet, and blue colors indicating increasing levels of decay (Anonymous 2004). However, all the images except one were brown in color, indicating the fastest acoustic transmission times possible which is normally associated with entirely solid wood. This meant that according to the Picus instrumentation and software, as used according to the manufacturer's recommendations, all the trees except for one tree were entirely free of wood decay at $0.3 \mathrm{~m}$ in height. However, Wang et al. (2009) found that the light brown color in the Picus image corresponded to incipient decay in wood. Therefore, rather than discount the Picus results, it was decided to reexamine the thirty-five solid brown images for differences in brightness as well as hue.

Each of the Picus images were converted to a monochrome 8-bit image using the ImageJ program (Rasband 2008). The darkest areas (areas where acoustic waves travel fastest) were used as reference, but the threshold for significant variation of acoustic speed was reset to identify potentially decayed areas. In ImageJ, this was achieved by highlighting the area of interest (lighter colored areas) in red (shown in white on Figure 2b). The threshold numerical upper and lower setting in ImageJ for highlighting light colored areas in red on the images was set identically for images that corresponded to the larger trees (over $200 \mathrm{~mm}$ in diameter at $0.3 \mathrm{~m}$ in height) where eight sensors were used, thus removing any subjectivity in assessing the brightness of the image. In calculating the estimated decay the "cogwheel" effect, lighter areas appearing at the midpoint between the locations of each sensor (Anonymous 2004) were not removed from the images as it was judged that this would be reintroducing an element of subjectivity back into the analysis. A different (lower) numerical threshold setting was used for the smaller trees that required the use of only six sensors (trees less than or equal to $200 \mathrm{~mm}$ in diameter at 0.3 $\mathrm{m}$ ) as all measurements (in this case both acoustic and distance) are more sensitive to error as they get smaller. In this way the false color output was re-calibrated through the imaging software. The percentage areas of decay were then calculated in cross-section.

\section{Wood Decay Estimation Method \#2: The Resi System}

The second method used a previously designed, but slightly modified, method developed by Johnstone et al. (2007) and combines the IML-Resi raw data (Figure 3a) and Shigo's (1979) compartmentalization of decay in trees (CODIT) model to predict the quantity of wood decay beyond the linear drill locations of the IML-Resi. This method relied on the experienced use of the IML-Resi, knowledge of models of decay in trees, and image analysis software.

The same Eucalyptus saligna Sm. (Bateman's Bay) were tested with the IML-Resi F300S as were tested with the Picus and at the same height. Sections were drilled twice from north to south and west to east, unless sections were more $300 \mathrm{~mm}$ in diameter at the test point in which case they were drilled three times. When

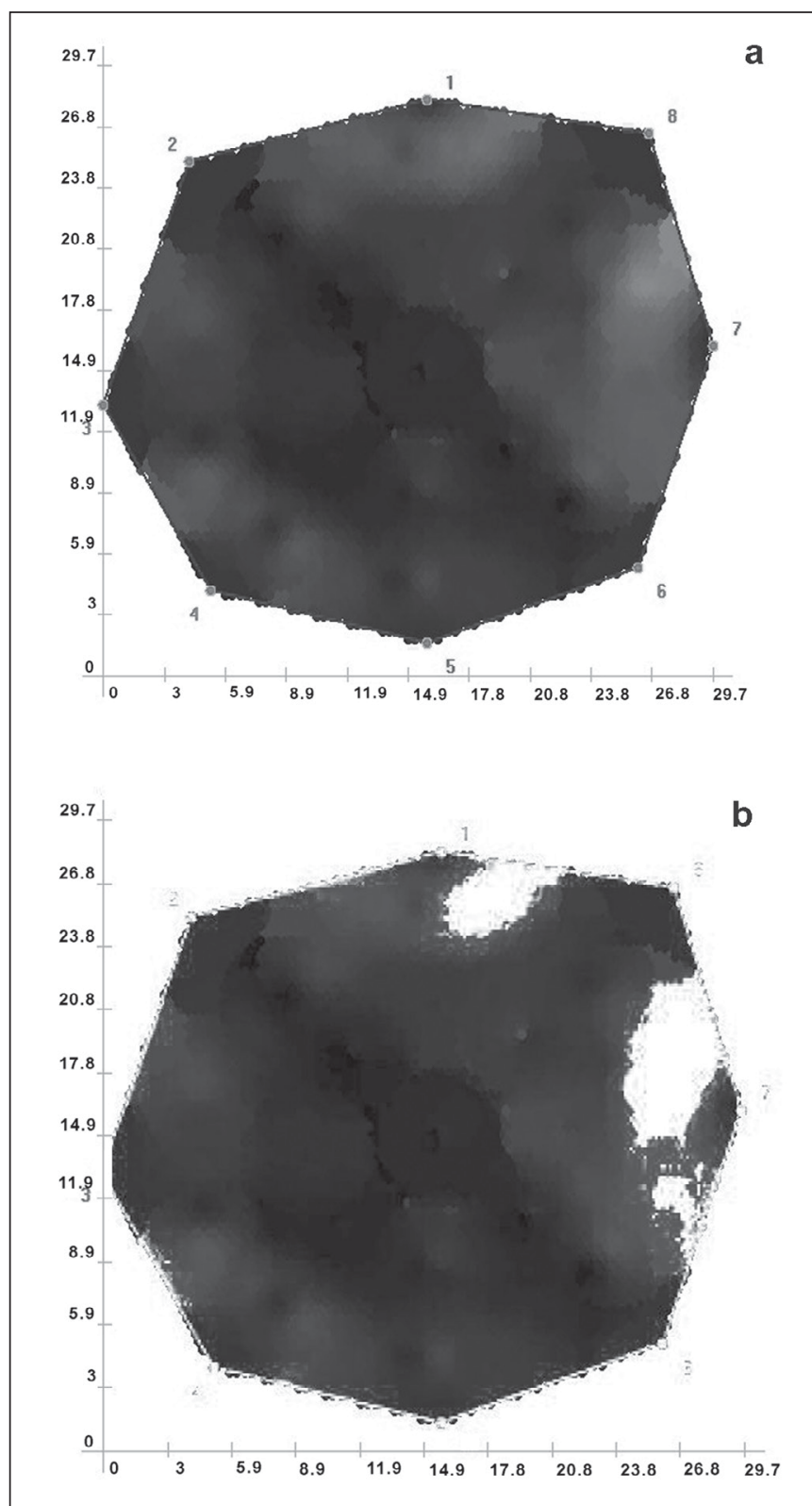

Figure 2. (a) An original Picus image using eight sensors for tree \#32. Image was solid brown with lighter brown areas. (b) The image after analysis with ImageJ. The red areas of interest were converted to white with Adobe Photoshop CS2 version 9.0.2. White is putative decay.

a graph trace on a tree $300 \mathrm{~mm}$ or less was difficult to interpret, the tree was also drilled three times to verify the decay location, slightly below and from the opposite direction to the original drilling position. After the sections were drilled, the graph traces were examined for decay according to the Resi System as described in previous research (Johnstone 2005; Johnstone et al. 2007) (Figure 3a). The signs of putative decay on the graph trace include yield in the trace and a lack of the symmetrical resistance pattern that indicates healthy growth increments (Johnstone 2005; Johnstone et al. 2007) (Figure 3a). Yield on the trace that was less than $10 \mathrm{~mm}$ in length was not recorded as this has been found to lead to errors (Johnstone 2005; Johnstone et al. 2007) (Figure 3a). 


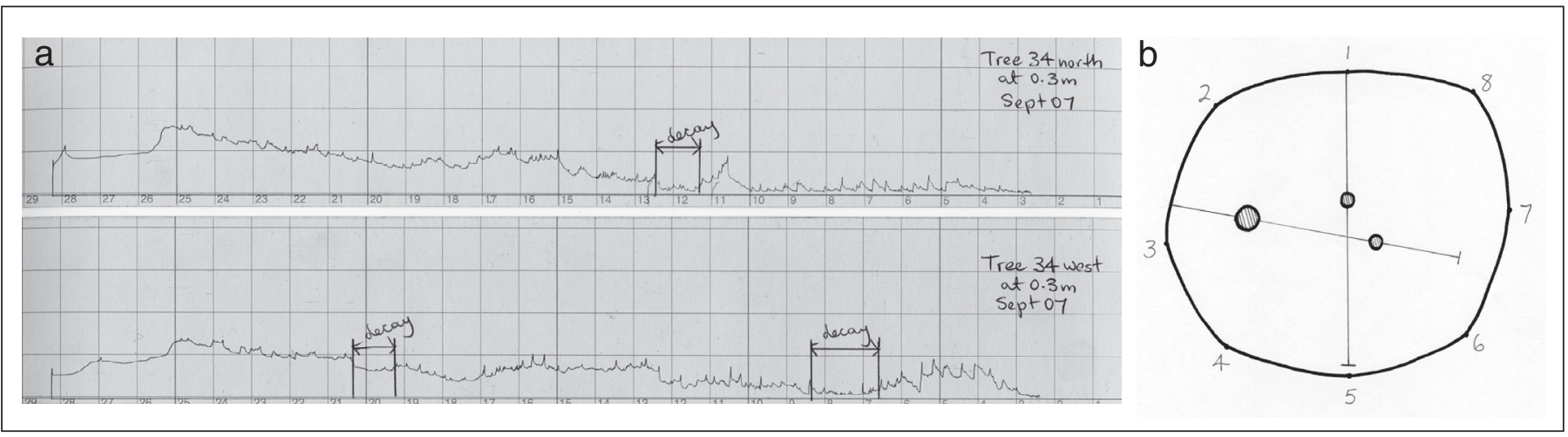

Figure 3. (a) The Resi graph trace for tree \#32 with putative decay marked on the trace. (b) Resi method diagram for tree \#32. Putative decayed areas are shaded. The trees were renumbered during the study.

Cross-sectional areas were calculated as described previously for the Picus system, using linear distance measurements and the Picus software and quantifying the area with ImageJ software for perimeter drawings and area calculations. The Resi system was further applied with reference to Shigo's CODIT model, and cross-sectional diagrams showing putative decay were drawn (Shigo 1979; Johnstone 2005; Johnstone et al. 2007) (Figure 3b). Although data for the decay assessment was collected from only two or three drill points, the accuracy of this method was shown to be around $75 \%$ in a previous study, justifying the use of a similar method in this study (Johnstone 2005; Johnstone et al. 2007). Each diagram was then scanned and the shaded putative decayed areas were quantified using ImageJ software. The percentage of estimated decay in each cross-section according to the Resi system was then calculated.

\section{Wood Decay Estimation Method \#3: The Visual Method}

In April 2008, the same 36 Eucalyptus saligna trees were cut down and the cross-sections at $0.3 \mathrm{~m}$ were retained for each tree. These cross-sections were sanded with an "Ozito" 730 watt electric belt sander and oiled with "Sweeney's Weatherproof Oil" (a mix of linseed oil, turpentine, and a binding agent) to highlight possible areas of decay (Figure 4a). As the sections were highly pigmented a needle probe inserted to a depth of 2 $\mathrm{mm}$ (Figure $4 \mathrm{~b}$ ) was used to verify the estimated visual decayed area in each section. The decay assessed was therefore advanced and/or intermediate and not assessed to the level of early decay and/or incipient decay in this method (Harris et al. 2004).

\section{Wood Moisture Content and Basic Density Estimation}

When the Eucalyptus saligna trees were cut down, a small trunk wood sample approximately $25 \mathrm{~mm}$ in height and $25 \mathrm{~mm}$ across was taken from north to south through the pith at $1.5 \mathrm{~m}$ in height. Samples were taken at a consistent aspect and height so that the variation in sample data could be controlled. No decay was visible in any of these samples. The samples were weighed immediately in the field using a balance. Each sample was then wrapped in plastic, and the green volume of the sample was calculated using the water displacement method (Walker et al. 1993). The average volume of wood samples was $119.1 \mathrm{~cm}^{3}$, they ranged in volume from $34.7 \mathrm{~cm}^{3}$ (tree \#28) to $238.2 \mathrm{~cm}^{3}$ (tree \#10).
The samples were oven dried and weighed every 24 hours in an oven of double shell construction at $105^{\circ} \mathrm{C}$ until they were no longer losing weight - they were dried for a total of 94 hours. Wood moisture content was then estimated as: [(original weight —oven dry weight)/original weight] x 100 (Walker et al. 1993). Basic wood density was estimated as: oven dry mass of wood/volume of wood when green (Walker et al. 1993).

\section{Statistical Analysis of Data}

Power analysis was conducted to determine sample size (the number of trees) that should be used in the study to detect important statistical relationships (Lenth 2001). It was determined that there would be enough statistical power (>

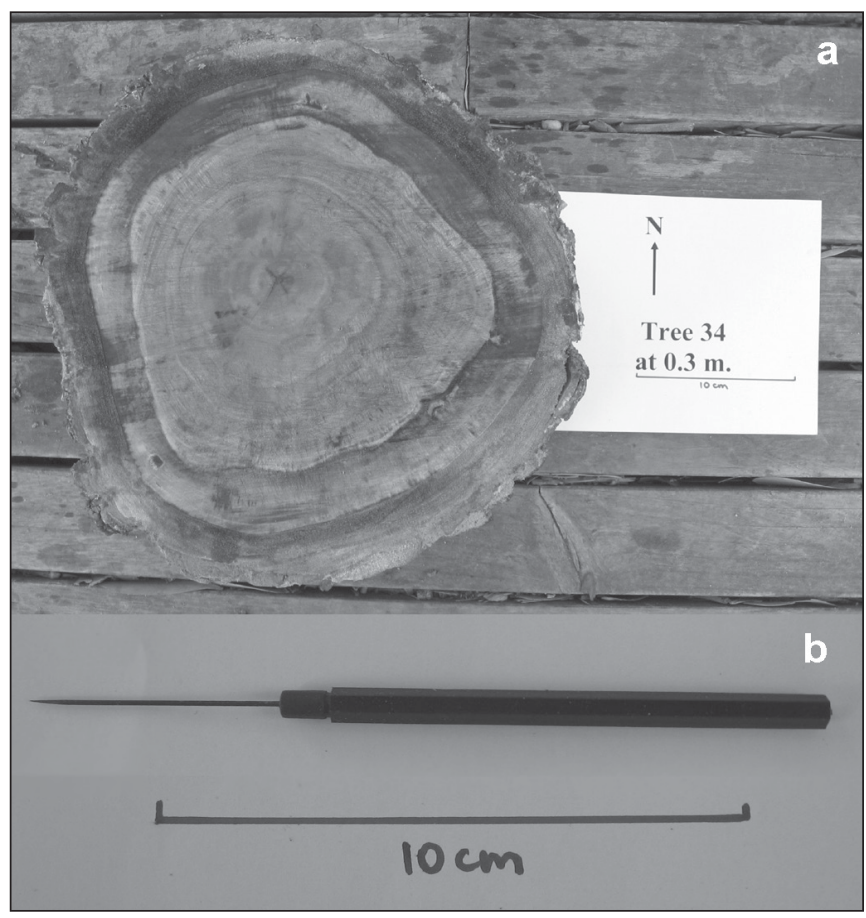

Figure 4. (a) A cross-section used for estimating the percentage of wood decay in a tree according to the visual method used in this study. (b) The needle probe used as part of the visual method. Tree shown is tree \#32, as the trees were renumbered after initial data collection. This tree was calculated as having $0.32 \%$ decay using the visual method of decay estimation. 
$80 \%$ ) in the analysis if $25-30$ samples were used (Lenth 2006). In order to allow for inaccuracies in data collection, 36 Eucalyptus saligna trees were used in this study.

A comparison was made between three methods of decay estimation and the estimation of whole tree wood density and also the wood moisture content and basic wood density at $1.5 \mathrm{~m}$. Simple linear and logarithmic regression analysis was calculated using the software package SAS (Statistical Analysis System) version 9.1. Multiple regression analysis comparing the three methods of decay estimation (as dependent variables) and the whole tree wood density and basic wood density (as independent variables) was performed to assess the statistical relationship between the decay estimations and whole tree wood density independently of each trees' basic wood density. Whole tree wood density and basic wood density were tested for multicolliniarity in order to validate the results from the multiple regression analysis.

The Picus system method for one tree (tree \#24) was not consistent with the other trees as this tree's Picus image was not a uniform color. Tree \#24 therefore became a statistical outlier in any analysis with the Picus system and was therefore removed from any analysis with the Picus system. Tree \#24 was also a "smaller" tree (less than or equal to $200 \mathrm{~mm}$ in diameter at $0.3 \mathrm{~m}$ in height), so the analysis of larger trees only also excluded tree \#24.

\section{RESULTS}

The Resi system showed a statistical correlation with the volume of wood decay in the Eucalyptus saligna trees as measured by the whole tree wood density and the Picus system and the visual method did not show a correlation. Basic wood density at $1.5 \mathrm{~m}$ did not show a statistical correlation with the Picus system or the visual method, but there was a statistical correlation between basic wood density at $1.5 \mathrm{~m}$ and the Resi system. There was also a significant linear and logarithmic relationship between basic wood density and whole tree wood density (Linear, $\mathrm{N}=36, \mathrm{P}=0.0064$, $\mathrm{r}^{2}=0.1988$; Logarithmic, $\left.\mathrm{N}=36, \mathrm{P}=0.0058, \mathrm{r}^{2}=0.2030\right)$. The results also suggest that the percentage wood moisture content and at $1.5 \mathrm{~m}$ does not affect the Picus system, the Resi system, or the visual method of decay estimation in Eucalyptus saligna trees.

\section{Results for the Picus System}

The relationship between the picus system and whole tree wood density was not statistically significant $(\mathrm{P}<0.05)$ using linear analysis $\left(\mathrm{N}=35, \mathrm{P}=0.1199, \mathrm{r}^{2}=0.0717\right)$, or logarithmic analysis $\left(\mathrm{N}=35, \mathrm{P}=0.1259, \mathrm{r}^{2}=0.0695\right)$ (Figure 5a).

All the trees that were larger than $200 \mathrm{~mm}$ in diameter at 0.3 $\mathrm{m}$ in height were analyzed separately because, as previously discussed, the Picus system for smaller trees was slightly different because the smaller diameter trees could only accept six Picus acoustic sensors. However there was still no statistically significant linear or logarithmic relationship between whole tree wood density and the Picus system (Linear, $\mathrm{N}=30, \mathrm{P}=0.0787, \mathrm{r}^{2}=$ 0.1063; Logarithmic, $\mathrm{N}=30, \mathrm{P}=0.0798, \mathrm{r}^{2}=0.1056$ ) (Figure 5b).

There was no linear or logarithmic relationship between the Picus system data and the basic wood density of the trees measured at $1.5 \mathrm{~m}$, even when the smaller trees were removed (Linear, $\mathrm{N}=30, \mathrm{P}=0.1180, \mathrm{r}^{2}=0.0846$; Logarithmic, $\mathrm{N}=30, \mathrm{P}$ $\left.=0.1142, r^{2}=0.0867\right)$. However, whole tree wood density and basic density showed a very significant linear and logarithmic relationship (Linear, $\mathrm{N}=36, \mathrm{P}=0.0064, \mathrm{r}^{2}=0.1988 ; \mathrm{N}=36$,

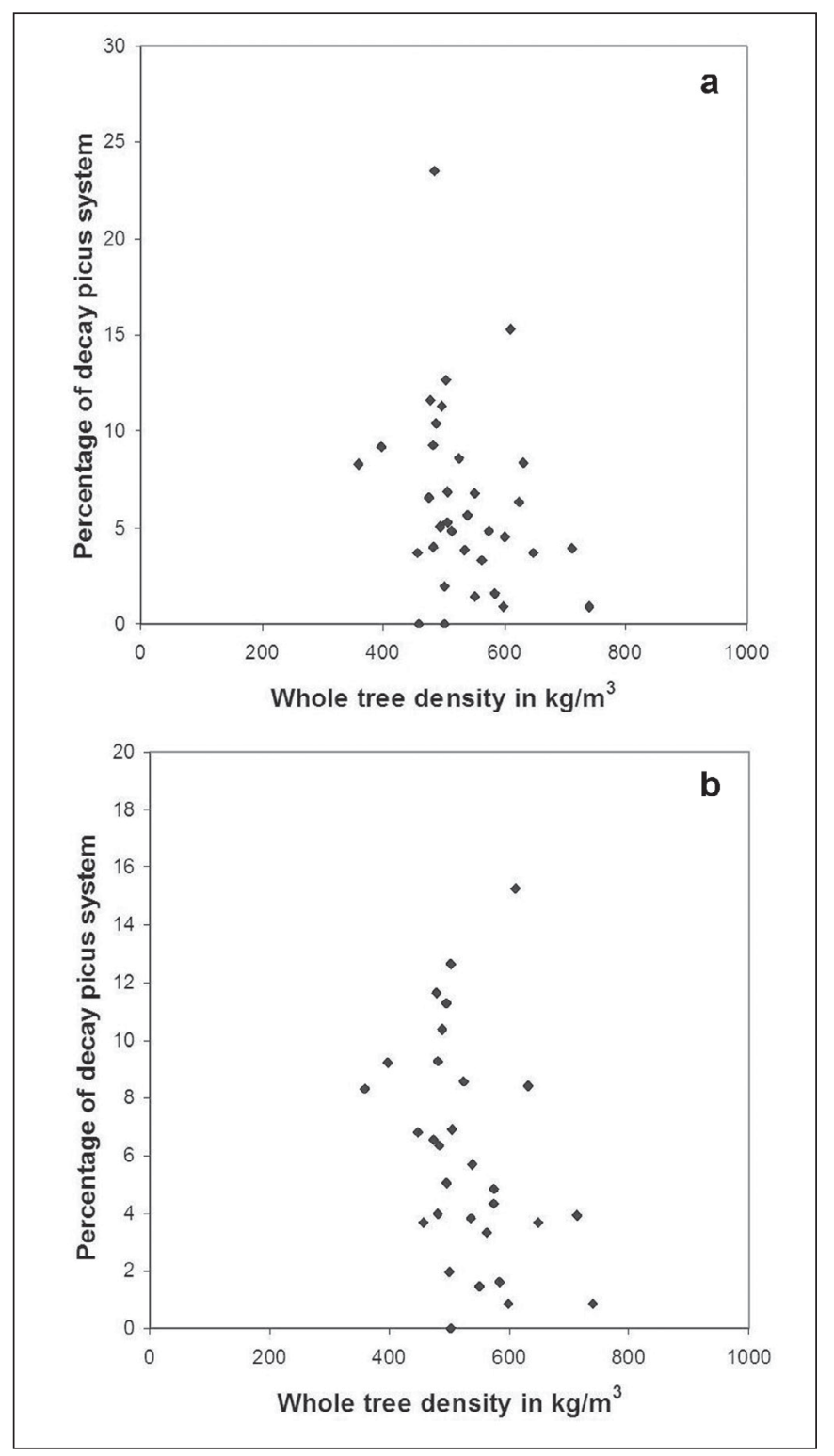

Figure 5. (a) The percentage of decay using the Picus system versus the whole tree wood density in $\mathrm{kg} / \mathrm{m}^{3}$, excluding tree \#24. Tree \#24 is an outlying data point in the Picus system data set; therefore, 35 Eucalyptus saligna trees are included in this data set. (b) The percentage of decay using the Picus system versus the whole tree wood density in $\mathrm{kg} / \mathrm{m}^{3}$. These data exclude trees less than or equal to $200 \mathrm{~mm}$ in diameter at $0.3 \mathrm{~m}$ in height, that is trees \#17, \#19, \#24, \#25, \#31, and \#34. Therefore 30 Eucalyptus saligna trees are included in this data set.

Logarithmic, $\mathrm{N}=36, \mathrm{P}=0.0058, \mathrm{r}^{2}=0.2030$ ). Multiple regression analysis was performed comparing the Picus system as a dependent variable and whole tree wood density and basic density as independent variables. There was no statistical relationship between whole tree wood density and the Picus system data, even when the interaction between the whole tree wood density and basic wood density was removed via multiple regression analysis $[\mathrm{N}=35, \mathrm{P}$ (whole tree) $=0.3712, \mathrm{P}$ (basic density) $\left.=0.2185, r^{2}=0.1153\right]$. When only larger trees were analyzed there was still no statistically significant relationship 
$[\mathrm{N}=30, \mathrm{P}($ whole tree $)=0.2100, \mathrm{P}$ (basic density $)=0.3332$, $\left.\mathrm{r}^{2}=0.1373\right]$. Tests such as the variance inflation factor (VIR) on whole tree wood density and basic density revealed very little multicolliniarity for these independent variables in the multiple regression analysis (VIR $<2$ in all cases). There was no linear or logarithmic statistical relationship between the Picus system data and the percentage of wood moisture content even when all the smaller trees were excluded (Linear, $\mathrm{N}=30, \mathrm{P}=0.4149$, $r^{2}=0.0239 ;$ Logarithmic, $\left.\mathrm{N}=30, \mathrm{P}=0.4072, \mathrm{r}^{2}=0.0247\right)$.

\section{Results for the Resi System}

The relationship between the Resi system and whole tree wood density was statistically significant $(\mathrm{P}<0.05)$ using linear analy-

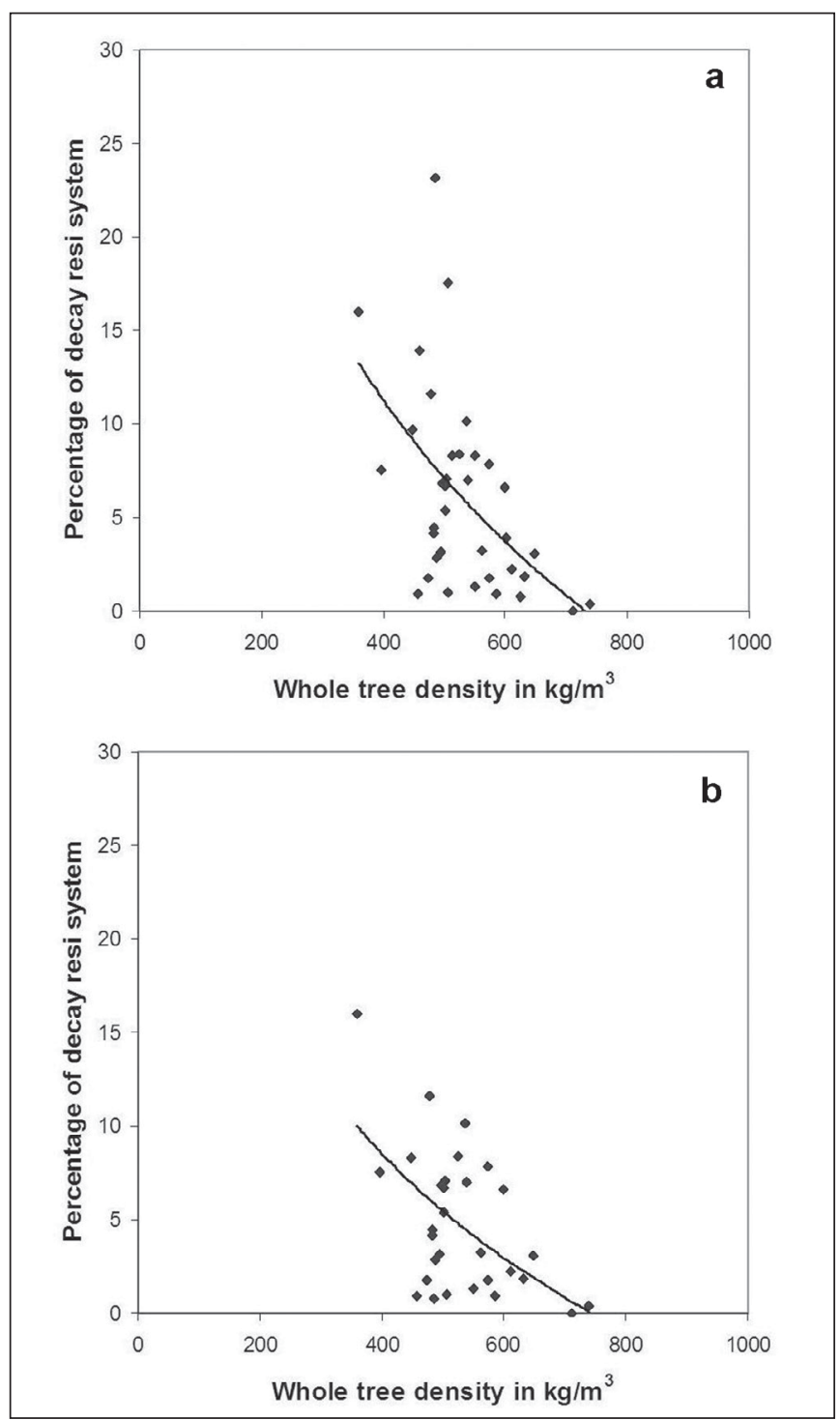

Figure 6. (a) The percentage of decay using the Resi system versus whole tree wood density in $\mathrm{kg} / \mathrm{m}^{3}$. Includes all 36 Eucalyptus saligna trees. Trend line $=$ logarithmic regression, $P=0.0027$, $r^{2}=0.2354$. (b) The percentage of decay using the Resi system versus the whole tree wood density in $\mathrm{kg} / \mathrm{m}^{3}$. These data exclude the smaller trees \#17, \#19, \#24, \#25, \#31, and \#34; therefore, 30 Eucalyptus saligna trees are included in this data set. Trend line $=$ logarithmic regression, $P=0.0015, r^{2}=0.3061$. ses $\left(\mathrm{N}=36, \mathrm{P}=0.0030, \mathrm{r}^{2}=0.2307\right)$. Logarithmic statistical relationships between whole tree wood density and the Resi system were more significant than the linear relationships (Logarithmic, $\left(\mathrm{N}=36, \mathrm{P}=0.0027, \mathrm{r}^{2}=0.2354\right.$, Figure 6a). The linear and logarithmic statistical relationship between whole tree wood density and the Resi system was more significant when the trees less than or equal to $200 \mathrm{~mm}$ in diameter at $0.3 \mathrm{~m}$ in height were excluded from the analysis (Linear, $\mathrm{N}=30, \mathrm{P}=0.0025, \mathrm{r}^{2}=0.2835$; Logarithmic, $\mathrm{N}=30, \mathrm{P}=0.0015, \mathrm{r}^{2}=0.3061$ ) (Figure $6 \mathrm{~b}$ ).

There was a linear and logarithmic relationship between the Resi system data and the basic wood density of the trees measured at $1.5 \mathrm{~m}$ (Linear, $\mathrm{N}=36, \mathrm{P}=0.0431, \mathrm{r}^{2}=0.1150$; Logarithmic, $\mathrm{N}=36, \mathrm{P}=0.0378, \mathrm{r}^{2}=0.1208$ ), but not when the smaller trees were excluded from analysis (Linear, $\mathrm{N}=30, \mathrm{P}=0.3503, \mathrm{r}^{2}=$ 0.0312 ; Logarithmic, $\left.\mathrm{N}=30, \mathrm{P}=0.3388, \mathrm{r}^{2}=0.0327\right)$. There was no linear or logarithmic statistical relationship between the Resi system data and the percentage of wood moisture content even when all the smaller trees were excluded (Linear, $\mathrm{N}=30, \mathrm{P}=$ $0.5682, \mathrm{r}^{2}=0.0118 ;$ Logarithmic, $\mathrm{N}=30, \mathrm{P}=0.5286, \mathrm{r}^{2}=0.0143$ ).

Multiple regression analysis was performed comparing the Resi system as a dependent variable and whole tree wood density and basic density as independent variables, to remove basic density as a factor influencing the relationship between whole tree wood density and the Resi system. There was a significant statistical relationship between whole tree wood density and the Resi system data $[\mathrm{N}=36, \mathrm{P}($ whole tree $)=0.0203, \mathrm{P}($ basic density $)=0.3613$, $\left.r^{2}=0.2502\right]$, which became even more significant when only the larger trees were analyzed $[\mathrm{N}=30, \mathrm{P}$ (whole tree) $=0.0045, \mathrm{P}$ (basic density) $\left.=0.8200, \mathrm{r}^{2}=0.2849\right]$. Tests such as the variance inflation factor (VIR) on whole tree wood density and basic density revealed very little multicolliniarity for these independent variables in the multiple regression analysis (VIR $<2$ in all cases).

\section{Results for the Visual Method}

The relationship between the visual method and whole tree wood density was not statistically significant $(\mathrm{P}<0.05)$ in linear and logarithmic analysis (Linear, $\mathrm{N}=36, \mathrm{P}=0.5150, \mathrm{r}^{2}=0.0126$; Logarithmic, $\mathrm{N}=36, \mathrm{P}=0.5530, \mathrm{r}^{2}=0.0104$ ) (Figure 7a). Even when only the larger trees were included, there was no significant statistical relationship between the visual method and whole tree in either linear or logarithmic analysis (Linear, $\mathrm{N}=30$, $\mathrm{P}=0.5759, \mathrm{r}^{2}=0.0113 ;$ Logarithmic, $\mathrm{N}=30, \mathrm{P}=0.6286, \mathrm{r}^{2}=$ $0.0085)$ (Figure 7b). Tree \#26 (13.53\%) and tree \#21 (8.07\%) were not deemed outlying data points for statistical analyses in the visual method of decay estimation, as the decay in this crosssection was clearly visible and easy to verify as correct, as were all cross-sections used to estimate decay using the visual method.

There was no linear or logarithmic statistical relationship between the visual method data and the percentage of wood moisture content even when all the smaller trees were excluded (Linear, $\mathrm{N}=30, \mathrm{P}=0.6555, \mathrm{r}^{2}=0.0072$; Logarithmic, $\mathrm{N}=30, \mathrm{P}=0.6703, \mathrm{r}^{2}=0.0066$ ). Also there was no relationship between the visual method data and the basic wood density of the trees measured at $1.5 \mathrm{~m}$, even when the smaller trees were excluded from analysis (Linear, $\mathrm{N}=30, \mathrm{P}=0.2364$, $\mathrm{r}^{2}=0.0497$; Logarithmic, $\left.\mathrm{N}=30, \mathrm{P}=0.2416, \mathrm{r}^{2}=0.0486\right)$.

Multiple regression analysis was performed comparing the visual method as a dependent variable and whole tree wood density and basic density as independent vari- 


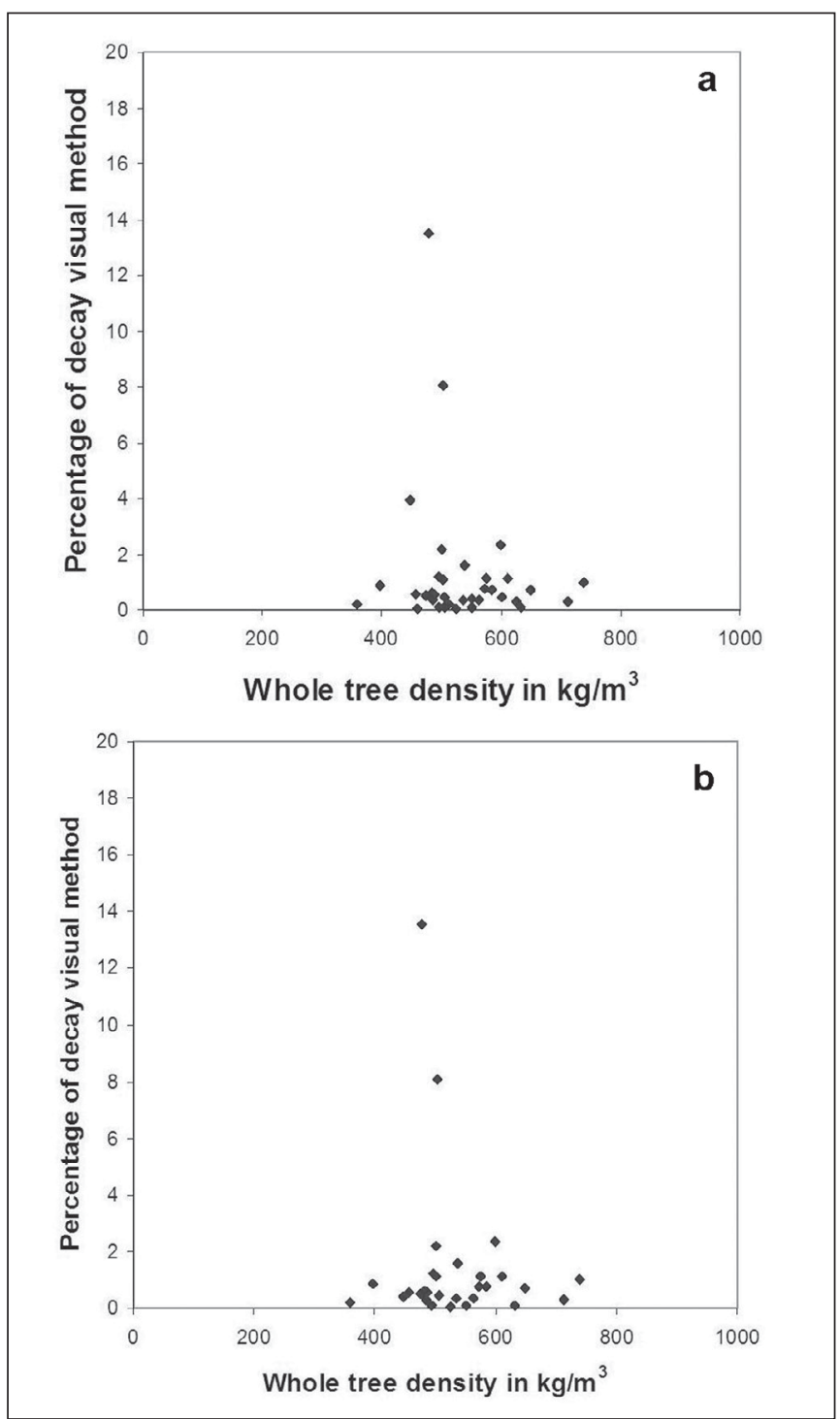

Figure 7. (a) The percentage of decay using the visual method versus the whole tree wood density in $\mathrm{kg} / \mathrm{m}^{3}$. Includes all 36 Eucalyptus saligna trees. (b) The percentage of decay using the visual method versus the whole tree wood density in $\mathrm{kg} / \mathrm{m}^{3}$. These data exclude smaller trees; trees \#17, \#19, \#24, \#25, \#31, and \#34 are excluded. Therefore, 30 Eucalyptus saligna trees are included in this data set.

ables. There was no significant statistical relationship between whole tree wood density and the visual method data, even when only larger trees were analyzed $[\mathrm{N}=30, \mathrm{P}$ (whole tree $)=0.9174, \mathrm{P}=($ basic density $\left.)=0.3032, \mathrm{r}^{2}=0.0501\right]$.

\section{DISCUSSION}

In this study, the estimation of wood decay given by the Resi system showed a statistical correlation to the volume of wood decay in Eucalyptus saligna, whereas the Picus system and the visual method of wood decay estimation did not show a statistical correlation. The accuracy of the Resi system is supported by Costello and Quarles (1999), who showed the Resistograph had a very low deviation from accuracy in assessing wood decay in Victorian bluegum (Eucalypus globulus).
There was a very small variation in the estimated volume of decay using the visual method, from only approximately $0.03 \%$ (tree \#19), to $13.53 \%$ (tree \#26), with $94 \%$ (all but two trees) estimated as having less than $4 \%$ wood decay. The small variation in data would have contributed to the lack of statistical relationships between the visual method and whole tree wood density. The decay in a wood section must be advanced or at least at an intermediate level in order to be detected with this method. To be advanced, the wood becomes fibrous and the wood structure is altered or nonexistent (Harris et al. 2004). Intermediate means the decay is clearly recognizable and there is a change in wood structure but remains intact. The other two stages - early decay, where there are slight changes in wood color, texture, and brittleness; and the incipient stage of decay, where there is a thinning of xylem cell walls and wood may be discolored-are not able to be detected by the visual method.

Basic wood density measured at $1.5 \mathrm{~m}$ also showed a correlation with the percentage of decay as calculated using the Resi system. This is not surprising as decay results in a decrease in wood density or mass (Beall and Wilcox 1987). Much of the wood strength in decaying wood is believed to be lost at incipient decay level, with up to $50 \%$ by around $1 \%$ mass loss (Beall and Wilcox 1987). Five to ten percent mass loss can only be detected by light microscopy, and is not yet visible (Beall and Wilcox 1987). Slight changes in wood density may not be detected by the visual method if only at the early or incipient level, but may be measureable using the Resi system described in this paper. The IML-Resi and the Resistograph showed clear correlations between basic density and raw drill resistance values in many studies that did not apply the Resi system described here (Rinn et al. 1996; Isik and Li 2003; Lin et al. 2003; Johnstone 2005). However applying the Resi system described here locates pockets of lower drill resistance that indicate putative decay (Figure 3b), not overall reduced drill resistance compared to other trees. The basic wood density measurement, as a sample taken across the whole of each tree at $1.5 \mathrm{~m}$ may be of reduced density due to incipient decay in the samples.

Whole tree wood density and basic density showed a very significant linear and logarithmic relationship. This is not surprising as whole tree dry density is strongly influenced by the density of the sound wood, as well as the decayed wood in a tree, particularly if the estimated volumes of decay are relatively low, as in this study [Picus system (excluding tree \#24) between $0 \%$ and $23.5 \%$, Resi system between $0 \%$ and $23.19 \%$, visual method between $0.03 \%$ and $13.53 \%$ ]. Separating a measure of decay and a measure of wood density is difficult and may require sophisticated measurements of the exact density across a wood section, such as SilviScanII, which was beyond the scope of this study (Evans et al. 1995). Multiple regression analysis was performed comparing each decay estimation method as a dependent variable and whole tree wood density and basic density as partial regression coefficients, in an attempt to remove the interplay between these two variables. The Resi system still showed a significant correlation with the whole tree wood density coefficient within the multiple regression.

The Resi system and the Picus system are both nondestructive methods of wood decay assessment, however there is considerable debate over whether the Resi drilling causes further wood decay in trees with some researchers claiming the damage is negligible (Weber and Mattheck 2006), while others imply it may be significant (Kersten and Schwarze 2005; Helliwell 2007; 
Schwarze 2008). Most researchers agree the Picus Sonic Tomograph is less likely to contribute to further wood decay than a Resi drill, as nails are inserted only a few millimeters into the xylem with the former (Gilbert and Smiley 2004), rather than holes being drilled directly through the xylem with the drill.

However, it is clear from this and other studies that the Picus Sonic Tomograph does have difficulty with accurate decay estimation, such as when the origin of the decay is in the sapwood (Deflorio et al. 2008; Wang et al. 2009), when there are cracks and cavities present (Schwarze and Heuser 2006; Wang and Allison 2008; Wang et al. 2009), the location of the wood decay is not necessarily centrally located in a cross-section (Schwarze 2008), and as in this study where the trees are small (from 142 to $318 \mathrm{~mm}$ in diameter at $1.3 \mathrm{~m}$ in height). Even when wood decay is centrally located, Wang et al. (2009) reported the Picus can underestimate the amount of wood decay. As in this study, Wang et al. (2009) reported that the Picus cannot reliably detect small amounts of sapwood decay and insect holes in mostly sound wood.

The percentage wood moisture content measured at $1.5 \mathrm{~m}$ showed no statistical relationship with the Picus, Resi, or visual wood decay estimation methods in this study. This is a positive result for these methods, as it is unlikely that wood moisture content is causing unexplained variation in the wood decay estimation data. Moisture content did affect the Resistograph and the Decay Detecting Drill resistance values in some studies (Seaby 1991; Rinn et al. 1996; Lin et al. 2003), but moisture content did not affect average drill resistance in a previous study by Johnstone (2005). It is very probable the Resi system removes the variable of moisture content, if present, from the drill resistance raw data. Though the velocity of sound in wood is affected by moisture content (Mishiro 1996), the Picus system was not affected by moisture content in this study.

The unexplained residual variation when each wood decay estimation method is compared to whole tree wood density- the best proxy for "true" wood decay values-is quite high for both the Resi and Picus systems. It is greater than $70 \%$ in all cases, even when the statistical relationships are significant. The possible error in the Picus and Resi systems is probably high, as for example the "linear distance" measurements used in both methods may be affected by variable bark thickness between trees, which in turn affects the cross-sectional (wood) area of the trees at 0.3 $\mathrm{m}$. The most successful method, the resi system, is a more subjective method than the picus system, because interpreting graphs is subjective, particularly ascertaining a lack of growth increments, but also the yield in the graph can be obscured by "noise" from residual resistance evident on the graph (Johnstone 2005).

Tree risk assessment cannot be achieved without evaluating the amount of decayed wood in a tree, but the exact location and amount of decay is difficult to assess. It is not practical to measure the amount of wood decay in all the wood of every tree. Therefore, the capacity of a single measurement taken in cross-section to approximate the volume decay in the wood of a whole tree was the focus of this study. Overall the Resi system appears to be the most suitable method for estimating the volume of wood decay in Eucalyptus saligna trees.
Acknowledgments. We would like to acknowledge the support of the Department of Sustainability and Environment, Victoria, Australia, for the use of their plantation trees for this research. We would also like to thank our anonymous reviewers for their time and consideration of this paper.

\section{LITERATURE CITED}

Anonymous, 2004. Picus Sonic Tomograph Manual. Rostock, Germany, Argus electronic gmbh. 52 pp.

Beall, F., and W. Wilcox. 1987. Relationship of acoustic emission during radial compression to mass loss from decay. Forest Products Journal $37: 38-42$.

Casella, E., and H. Sinoquet. 2003. A method for describing canopy architecture of coppice poplar with allometric relationships. Tree Physiology 23:1153-1170.

Costello, L., and S. Quarles. 1999. Detection of wood decay in blue gum and elm: an evaluation of the IML-Resistograph and the portable drill. Journal of Arboriculture 25:311-317.

Deflorio, G., K.M. Barry, C. Johnson, and C.L. Mohammed. 2007. The influence of wound location on decay extent in plantation-grown Eucalyptus globulus and Eucalyptus nitens. Forest Ecology and Management 242:353-362.

Deflorio, G., S. Fink, and F.W.M.R. Schwarze. 2008. Detection of incipient decay in tree stems with sonic tomography after wounding and fungal infection. Wood Science Technology 42:117-132.

Evans, R., G. Gartside, and G. Downes. 1995. Present and prospective use of Silviscan - an instrument for the rapid measurement of wood properties. Research Report. Melbourne, The CRC for Hardwood Fibre \& Paper Science 47. 4 pp.

Gilbert, E., and E. Smiley. 2004. Picus sonic tomography for the quantification of decay in white oak (Quercus alba) and hickory (Carya spp.). Journal of Arboriculture 30:277-281.

Harris, R.W., J.R. Clark, and N.P. Matheny. 2004. Arboriculture. Integrated Management of Landscape Trees, Shrubs, and Vines (4th Edition). New Jersey, Prentice Hall. 578 pp.

Helliwell, D.R. 2007. A short note on effects of boring holes in trees. Arboricultural Journal 30:245-248.

Isik, F., and B. Li. 2003. Rapid assessment of wood density of live trees using the IML-Resistograph for selection in tree improvement programs. Canadian Journal of Forest Research 33:2426-2435.

Johnstone, D.M. 2005. The field assessment of wood decay and wood density in eucalypts. Master of Forest Science Thesis. University of Melbourne, Vic. 221 pp.

Johnstone, D.M., P.K Ades, G.M. Moore, and I.W. Smith. 2007. Predicting wood decay in eucalypts using an expert system and the IMLResistograph drill. Arboriculture \& Urban Forestry 33:76-82.

Kersten, W., and F.W.M.R. Schwarze. 2005. Development of decay in the sapwood of trees wounded by the use of decay-detecting devises. Arboricultural Journal 28:165-181.

Lenth, R.V. 2001. Some Practical Guidelines for Effective Sample Size Determination, The American Statistician 55:187-193.

Lenth, R.V. 2006. Java Applets for Power and Sample Size [Computer software]. Retrieved Sept. 26, 2009. <http://www.stat.uiowa. edu/ rlenth/Power>

Lin, C.-J., S.-Y. Wang, F.-C. Lin, and M.-C. Chiu. 2003. Effect of moisture content on drill resistance value in Taiwania plantation wood. Wood and Fiber Science 35:234-248. 
Matheny, N., J. Clark, D. Attewell, K. Hillery, A. Graham, and G. Posner. 1999. Assessment of fracture moment and fracture angle in 25 tree species in the United States using the fractometer. Journal of Arboriculture 25:18-23.

Mattheck, C. 2007. Updated Field Guide for Visual Tree Assessment. Karlsruhe Research Center Karlsruhe. 170 pp.

Mattheck, C., and H. Breloer. 1994. Field guide for visual tree assessment (VTA). Arboricultural Journal 18:1-23.

Mishiro, A. 1996. Effect of density on ultrasonic velocity in wood. Mokuzai Gakkaishi 42:887-894

Rasband, W. 2008. ImageJ version 1.40g, Image Processing and Analysis in Java USA National Institutes of Health, [Computer software]. Retrieved August 29, 2008. <http://rsbweb.nih.gov/ij/>

Rinn, F., F.H. Schweingruber, E. Schar. 1996. Resistograph and X-ray density charts of wood comparative evaluation of drill resistance profiles and X-ray density charts of different wood species. Holzforschung 50:303-311.

Schwarze, F.W.M.R. 2008. Diagnosis and Prognosis of the Development of Wood Decay in Urban Trees. Enspec, Vic. 336 pp.

Schwarze, F.W.M.R., and C. Heuser. 2006. Stem wounds - potential entry courts for wood decay fungi? Arboricultural Journal 29:101-119.

Seaby, D.A. 1991. Recent advances in detection of wood decay, pp. 168-176. In: Research for Practical Arboriculture. S.J. Hodge (Ed.). HMSO. University of York.

Shigo, A.L. 1979. Tree decay: an expanded concept. USDA Forest Service Information Bulletin 419. $72 \mathrm{pp}$.

Walker, J.C.F., B.G. Butterfield, T.A.G. Langrish, J.M. Harris, and J.M. Uprichard. 1993. Primary Wood Processing. Principles and Practice. Chapman \& Hall, London. 595 pp.

Wang, X., and R.B. Allison. 2008. Decay detection in red oak trees using a combination of visual inspection, acoustic testing, and resistance microdrilling. Arboriculture \& Urban Forestry 34:1-4.

Wang, X., J. Wiedenbeck, and S. Liang. 2009. Acoustic tomography for decay detection in black cherry trees. Wood and Fiber Science 41:127-137.

Weber, K., and C. Mattheck. 2006. The effects of excessive drilling diagnosis on decay propagation in trees. Trees Structure and Function 20:224-228.

Wilkes, J., and W.A. Heather. 1983. Correlation of resistance to a pulsed current with several wood properties in living eucalypts. New Zealand Journal of Forestry Science 13:139-135.
Denise Johnstone (corresponding author)

Department of Resource Management and Geography

Melbourne School of Land and Environment

University of Melbourne

500 Yarra Boulevard

Richmond, Victoria 3121

Australia

Michael Tausz

Associate Professor

Department of Forest and Ecosystem Science

Melbourne School of Land and Environment

University of Melbourne

Water Street

Creswick, Victoria 3363

Australia

Gregory Moore, Ph.D.

Department of Resource Management and Geography Melbourne School of Land and Environment

University of Melbourne

500 Yarra Boulevard

Richmond, Victoria, 3121

Australia

Marc Nicolas, Ph.D.

Department of Agriculture and Food Systems

Melbourne School of Land and Environment

The University of Melbourne

Parkville, Victoria 3010

Australia 
Résumé. L'évaluation du degré de carie du bois dans un arbre est essentielle pour quantifier le risque en arboriculture. Il est peu faisable en pratique de mesurer la quantité de bois carié sur l'ensemble du bois de tous les arbres. En conséquence, la capacité de prendre une seule mesure dans une section transversale pour estimer le volume de bois carié d'un arbre en entier est l'objectif central de cette étude. Le volume de bois carié chez des Eucalyptus saligna a été estimé après récolte en mesurant la densité du bois pour l'ensemble de 36 arbres. Des modèles statistiques linéaire, logarithmique et à régression multiple ont été employés afin d'examiner si la donnée de densité du bois chez l'arbre complet peut être corrélée avec trois méthodes de mesurer la carie du bois dans une section transversale, deux méthodes avant l'abattage de l'arbre et une méthode après l'abattage. Les mesures d'estimation de la carie ont été prises dans la section transversale au moyen de trois techniques: système tomographique Picus® Sonic, système IML-Resi et méthode visuelle. Dans cette étude, le système Resi pour estimer le degré de carie a démontré une corrélation avec la densité en bois de l'ensemble de l'arbre tandis que le système Picus et la méthode visuelle n'ont démontré aucune corrélation statistique avec le densité en bois de l'ensemble de l'arbre.

Zusammenfassung. In die Baumpflege ist die Bewertung von faulem Holz in einem Baum essentiell für die Risikobewertung. In der Praxis ist eine Messung des Anteils vom faulem Holz in dem Holz jedes Baumes nicht durchführbar. Daher ist der Fokus dieser Studie, die Kapazität einer einzigen Messung aus dem Querschnitt zur Bestimmung des Fäulevolumes zu erfassen. Deas Fäulevolumen von 36 Eucalyptusbäumen wurde nach der Holzernte durch Messung der Holzdichte geschätzt. Lineare, logarythmische und multiple statistische Degressionsmodelle wurden verwendet, um zu bestimmen, ob die Daten zur Holzdichte des ganzen Baumes korreliert werden können mit drei verschiedenen Wegen der direkten Messung in einem Querschnitt, zwei vor der Fällung, einer nach der Fällung. Die Technik Fäulebestimmung setzt im Querschnitt an: ein Picus Sonic Tomograph, ein IML resistograph und eine reine Sichtkontrolle. In dieser Studie zeigte der Resistograph Korrelationen mit der Holzdichte im ganzen Baum, wo hingegen der Picus und die Sichtkontrolle keine statistisch verwertbaren Korrelationen mit der gemessenen Baumdichte zeigten.

Resumen. La medición de la madera descompuesta en los árboles es esencial para la evaluación del riesgo en la arboricultura. No es factible en la práctica medir la cantidad de madera descompuesta en todo el árbol. Por consiguiente, la capacidad de una sola medición tomada en la sección trasversal para aproximar el volumen de descomposición en la madera de un árbol es el foco de este estudio. Se estimó el volumen de madera descompuesta en 36 árboles de Eucalyptus saligna cosechados. Se utilizaron modelos lineales, logarítmicos y regresión estadística múltiple para examinar si la densidad de la madera podría estar correlacionada con tres formas de medición directa de la madera descompuesta en una sola sección trasversal, dos métodos antes y uno posterior a su derribo. Las técnicas de estimación fueron medidas en la sección trasversal con un sistema de Tomógrafo Picus® ${ }^{\circledR}$ Sonic, un sistema Resistógrafo IML y un método visual. En este estudio el sistema de Resistógrafo para la medición de la madera descompuesta mostró una correlación con la densidad de la madera en el árbol mientras el sistema Picus y el método visual no mostraron ninguna correlación estadística con la densidad de la madera. 